\title{
AN APPLICATION OF CLOSE-UP PHOTOGRAMMETRY IN VITICULTURE
}

\author{
Maria Grazia D'Urso ${ }^{a}, *$, Costantino Luis Marino ${ }^{b}$ \\ a *DICeM, Department of Civil and Mechanical Engineering, University of Cassino and Southern Lazio, \\ Via G. Di Biasio, 4303043 Cassino (Frosinone), Italy \\ durso@unicas.it \\ b International Surveyance Company, cm99@hotmail.it
}

KEY WORDS: camera, close-up photogrammetry, digital images, viticulture, mesh

\begin{abstract}
:
Within the context of Geomatic-based Agriculture an application of close-up photogrammetry is illustrated with reference to precision farming. The application has been carried out in a particularly attractive archaeological site and concerns some viticulture species produced in situ by following a farming technique dated about two thousand years. Specifically we illustrate and comment the photogrammetric close-range acquisitions, carried out both outdoor and indoor, aimed at producing a digital botanic atlas that can adequately replace the traditional ones drawn by hand. High precision geometric measurements of vineyard leaves and grapes, are suitable indices of their growth rate and an objective estimate of the relevant repening degree.
\end{abstract}

\section{INTRODUCTION}

The first example of italian ampelographic classification of vines (from Greek: $\not \alpha \mu \pi \varepsilon \lambda_{0} \varsigma=$ vine) dates to the Middle Age when, around the 1300 's, the scholar Piero Crescenzi carried out a classification study of the volumes and shapes of grapevines and vineyards known at that time. In particular, he produced two important botanic tables where about 37-38 different vines were already classified.

Subsequently, during the first half of the 1600's, the scholar Bartolomeo Bimbi authored a "viticulture catalog", basically an "artistic-scientific" work in this sector; but it was only in the 1879's that the Italian Ministry for Agriculture published the first Amphelographic Italian Collection, edited by the Central Ampelographic Committee.

Aim of this paper is to make a contribution to the realization of botanic tables, concerning the autochthonous vines produced in the archaeological areas of Pompei and Boscoreale, in the Campania district, effective for determining the morphological and oenological characteristics of the vineyards. Differently from researchers of the past, which used suggestive painting techniques for qualitative representation of the grapes, the approach exploited in this work is based on photogrammetric close-up technique since it allows one to determine, with high precision, shapes and extension of the grapevines, their dimension as well as that of bunches and leaves.

The innovation of the proposed approach for agriculture is represented by the possibility of having an extremely accurate control of the growth rate and to estimate the economic productivity of vineyards.

\section{FUNDAMENTAL PARAMETERS FOR THE PHOTOGRAMMETRIC SHOOTINGS CLOSE-UP}

For a close-up photogrammetric acquisition some optical parameters and characteristics are particularly important; specifically, they concern the depth of field, the sensitivity of the camera sensor, the dynamic range and the perfect signal transformation from analogical to digital. For these reasons cameras, lights and specific optics have been used in order to determine the dimensions of bunches and leaves of the grapes and to show the presence of possible parasites or illnesses. Grapes with lack of growth exhibit specific symptoms such as yellowing, redness, leaf dieback, blossoming, power setting fruit as well as small and deformed acini.

The experience has been carried out indoor and outdoor with colour shootings for obtaining an excellent visual output otherwise impossible with mono-chromatic views that would have generated sensibly less heavy images. Light control has been obtained in laboratory by using specific wave-lengths and illuminating beams so as to avoid shades and the flares (erroneous light diffraction inside the optics) which unavoidably characterize a field shooting, thus obtaining a three-dimensional image of the object in scale 1:1.

Several metric cameras and optics have been used: the first shooting has been executed by using a Canon 5Ds metric camera, with a Zeiss Makro Planar T 100 calibrated optics and relevant accessories. The second shooting has been executed by using a calibrated Micro Nikkor 105 calibrated optics and a Zeiss Otus $50 \mathrm{~mm}$ optics (Zeiss Carl AG Camera Lenses $73446 \quad$ Oberkochen, Germany, www.zeiss.com/photo).

The results have been absolutely the same with precision values having order of magnitude of a hundredth of millimeter. The use of highly professional macro optics is necessary in order to transfer information to the cameras sensors thus avoiding low quality optics characterized by a low resolution.

The close-up shooting requires standard test conditions: absolute immobility of the planes, lack of vibrations, presence of controlled shielded lights, use of optics with extremely closed diaphragm needed for increasing field depth. Operative conditions must ensure an environment with controlled values of temperature and humidity, thus avoiding even the minimum withering and deformation of the leaves.

\footnotetext{
* Corresponding author.
} 
The camera is fixed on a tripod or a support; alternatively, the grapevine is moved mechanically, on a rotating plane, by a $360^{\circ}$ angle, and shootings are taken every $15^{\circ}$ degrees. The main physical and geometric problem of the optics regards the field depth and is governed by very severe mathematical rules which defeat the use of last generation auto-focus cameras.

Hence, aperture of the diaphragm generates fixed focalization areas within which objects are actually visible, thus binding the shooting to strict and stable parameters values. As a consequence, shooting must be executed with a priori established conditions and it is necessary to provide the automatic digitalized systems shots lacking of out-of-focus areas. As an example Figure 1 shows field depths, expressed in centimeters, for a 100 millimeters optics as a function of the diaphragm aperture. Controlling field depth values is essential since the use of closed diaphragms, mandatory in a close-up shooting, allows one the correct shaping of the photographic image, by avoiding totally blurred areas that could produce blunders in the photogrammetric digital softwares.

\begin{tabular}{|c|c|c|c|c|c|c|c|}
\hline 2 & $\begin{array}{l}0,98 \\
1,00 \\
1,02\end{array}$ & $\begin{array}{l}1,40 \\
1,50 \\
1,5\end{array}$ & $\begin{array}{l}\begin{array}{l}2,2 \\
2,0 \\
2,00\end{array} \\
2\end{array}$ & $\begin{array}{l}2,3,50 \\
2,50 \\
2,63\end{array}$ & $\begin{array}{r}2,83 \\
3,00 \\
3,19\end{array}$ & $\begin{array}{r}3,27 \\
3,50 \\
3,76\end{array}$ & $\begin{array}{r}3,70 \\
4,00 \\
4,35 \\
4\end{array}$ \\
\hline 2,5 & $\begin{array}{l}0,98 \\
1,00 \\
1,03\end{array}$ & $\begin{array}{l}1,45 \\
1,50 \\
1,56\end{array}$ & $\begin{array}{l}1,90 \\
2,00 \\
2,11\end{array}$ & $\begin{array}{r}2,35 \\
2,50 \\
2,67\end{array}$ & $\begin{array}{l}2,79 \\
3,00 \\
3,24\end{array}$ & $\begin{array}{l}3,22 \\
3,50 \\
3,84\end{array}$ & $\begin{array}{l}3,64 \\
4,00 \\
4,44\end{array}$ \\
\hline 3 & $\begin{array}{l}0,97 \\
1,00 \\
1,03 \\
\end{array}$ & $\begin{array}{l}1,44 \\
1,50 \\
1,57\end{array}$ & $\begin{array}{l}1,89 \\
2,00 \\
2,13\end{array}$ & $\begin{array}{l}2,33 \\
2,50 \\
2,70\end{array}$ & $\begin{array}{l}2,75 \\
3,00 \\
3,30\end{array}$ & $\begin{array}{l}3,17 \\
3,50 \\
3,91\end{array}$ & $\begin{array}{l}3,57 \\
4,00 \\
4,55 \\
\end{array}$ \\
\hline 3,5 & $\begin{array}{l}0,97 \\
1,00 \\
1,04\end{array}$ & $\begin{array}{l}1,43 \\
1,50 \\
1,58\end{array}$ & $\begin{array}{l}1,87 \\
2,00 \\
2,15\end{array}$ & $\begin{array}{l}\begin{array}{l}2,30 \\
2,50 \\
2,74\end{array}\end{array}$ & $\begin{array}{l}2,70 \\
3,00 \\
3,35\end{array}$ & $\begin{array}{r}3,12 \\
3,50 \\
3,99\end{array}$ & $\begin{array}{l}3,51 \\
4,00 \\
4,65\end{array}$ \\
\hline 4 & $\begin{array}{l}0,96 \\
1,00 \\
1,04\end{array}$ & $\begin{array}{l}1,42 \\
1,50 \\
1,60\end{array}$ & $\begin{array}{l}1,85 \\
2,00 \\
2,17\end{array}$ & $\begin{array}{l}\begin{array}{l}2,27 \\
2,50 \\
2,78\end{array} \\
\end{array}$ & $\begin{array}{l}2,68 \\
3,00 \\
3,44\end{array}$ & $\begin{array}{l}3,07 \\
3,50 \\
4,07\end{array}$ & $\begin{array}{r}3.45 \\
4,00 \\
4,76\end{array}$ \\
\hline 4,5 & $\begin{array}{l}0,96 \\
1,00 \\
1,00 \\
\end{array}$ & $\begin{array}{l}1,41 \\
1,50 \\
1,61 \\
\end{array}$ & $\begin{array}{l}1,83 \\
2,00 \\
2,20\end{array}$ & $\begin{array}{l}2,25 \\
2,50 \\
2,82 \\
\end{array}$ & $\begin{array}{l}\text { 2,64 } \\
3,00 \\
3,47\end{array}$ & $\begin{array}{l}3,02 \\
3,50 \\
4,15 \\
\end{array}$ & $\begin{array}{r}3,39 \\
4,00 \\
4,88 \\
\end{array}$ \\
\hline 5,6 & $\begin{array}{l}0,95 \\
1,00 \\
1,00\end{array}$ & $\begin{array}{l}1,38 \\
1,50 \\
1,64\end{array}$ & $\begin{array}{l}1,80 \\
2,00 \\
2,25\end{array}$ & $\begin{array}{l}2,19 \\
2,50 \\
2,50\end{array}$ & 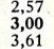 & $\begin{array}{l}2,93 \\
3,50 \\
4,35\end{array}$ & $\begin{array}{l}3,27 \\
4,00\end{array}$ \\
\hline 6,3 & $\begin{array}{l}0,94,0 \\
1,00\end{array}$ & $\begin{array}{l}1,1,50 \\
1,50 \\
1,6\end{array}$ & $\begin{array}{l}1,78 \\
2,00 \\
2,29\end{array}$ & $\begin{array}{l}2,16 \\
2,50 \\
2,97\end{array}$ & $\begin{array}{l}\begin{array}{l}3,525 \\
3,00\end{array} \\
3,70\end{array}$ & $\begin{array}{l}3,50 \\
3,59\end{array}$ & $\begin{array}{l}4,190 \\
4,05\end{array}$ \\
\hline 8 & $\begin{array}{l}x_{1,22} \\
1,10\end{array}$ & $\begin{array}{l}1,32 \\
1,50 \\
1,74\end{array}$ & $\begin{array}{l}1,69 \\
2,00 \\
2,45\end{array}$ & $\begin{array}{l}2,03 \\
2,50 \\
3,24\end{array}$ & $\begin{array}{l}2,35 \\
3,00 \\
4,13\end{array}$ & $\begin{array}{l}2,65 \\
3,50 \\
5,15\end{array}$ & $\begin{array}{l}2,93 \\
4,00 \\
6,31\end{array}$ \\
\hline 11 & $\begin{array}{l}0_{1,89}^{1,98} \\
1,1\end{array}$ & $\begin{array}{l}1,26 \\
1,50 \\
1,85\end{array}$ & $\begin{array}{l}1,60 \\
2,00 \\
2,67\end{array}$ & $\begin{array}{l}2,90 \\
2,50 \\
3,65\end{array}$ & $\begin{array}{l}2,1,180 \\
3,00 \\
4,82\end{array}$ & $\begin{array}{l}2,43 \\
3,50 \\
6,25\end{array}$ & $\begin{array}{r}2,660 \\
4,00 \\
8,05\end{array}$ \\
\hline 16 & $\begin{array}{l}0,85 \\
1,00 \\
1,22\end{array}$ & $\begin{array}{l}1,18 \\
1,50 \\
2,07\end{array}$ & $\begin{array}{l}1,46 \\
2,00 \\
3,15\end{array}$ & $\begin{array}{l}1,72,72 \\
2,50 \\
4,661\end{array}$ & $\begin{array}{l}3,94 \\
3,00 \\
6,65\end{array}$ & $\begin{array}{l}2,13 \\
3,50 \\
9,72\end{array}$ & $\begin{array}{r}2,31 \\
4,00 \\
14,89\end{array}$ \\
\hline
\end{tabular}

Figure 1. Field depth $(\mathrm{cm})$

As a matter of fact, it is clear by examining the first value of table in Figure 1 that a 1 meter focusing with a value of 2 for the diaphragm aperture produces, by taking into account the difference between the inferior and superior limits of the table, 4 centimeters of field depth. Conversely, focusing to the same distance but with a value of 16 for the diaphragm aperture, which represents the minimum value for a close-up shot, yields a value of 37 centimeters for the field depth. The different focusing of the two images is clearly represented in the Figures 2 and 3.

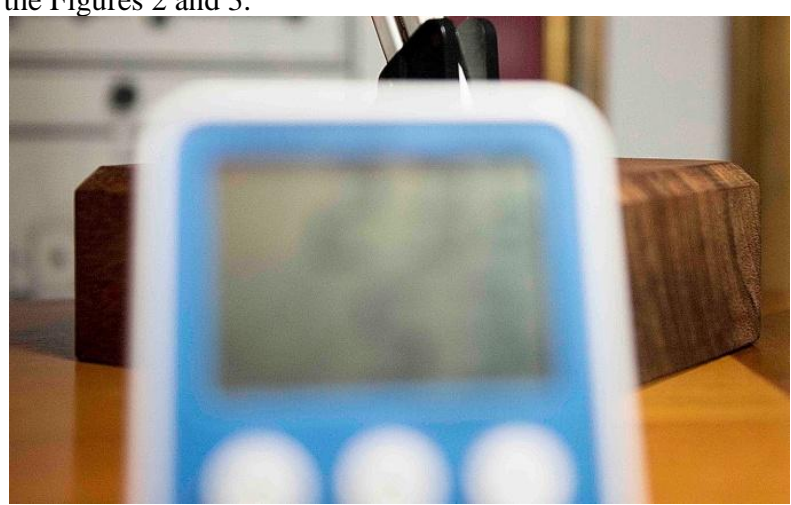

Figure 2. Image with a value of 2 for the diaphragm opening

Shooting speed has always been superior to $1 / 60$ of second (one sixtieth of second), although the cameras have damping systems of the vibrations produced by the shoot. It is apparent from Figure 4 that the ISO sensitivity of the camera sensor used in the described experience has been fixed to the value of 64 ISO, a nearly ideal value for the exposition, a value very near to the theoretical nominal value.

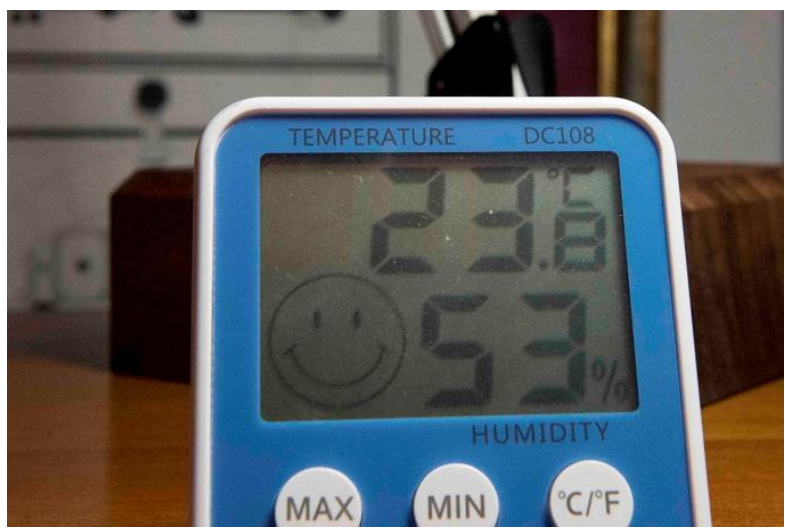

Figure 3. Image with a value of 16 for the diaphragm opening

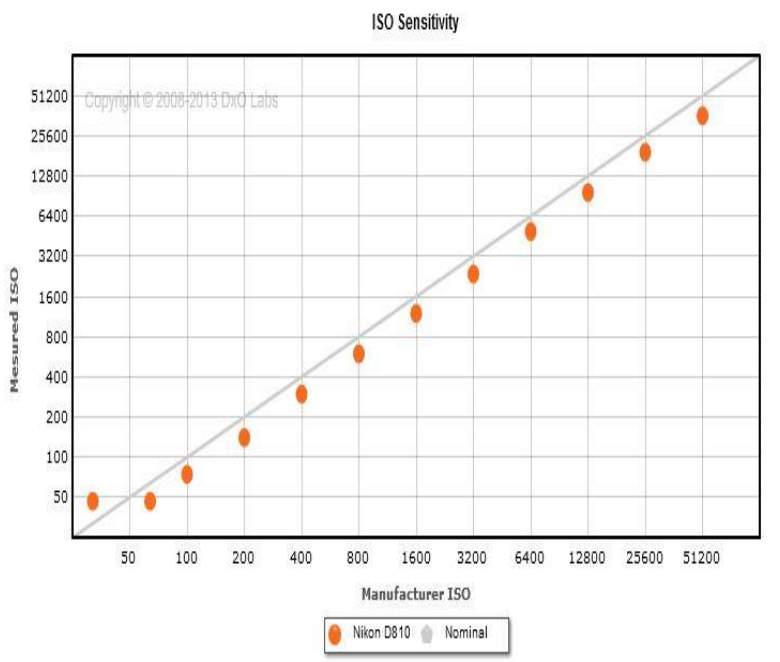

Figure 4. ISO sensitivity of the Nikon D810 sensor

The importance of the shooting dynamic range, representing the rate between light and dark areas (rate of contrast), is much more relevant in digital cameras. It is evident from the following illustration in Figure 5 that the values of the dynamic range extension for the cameras used in our experiments considerably differ each other and, in addition, turn out to be by far less than the dynamic range value of the human eye, which is equal to 24 diaphragms (DxOMark http://www.dxomark.com/).

Moreover, during the laboratory experiment it has been used a controlled illumination obtained from cold lights having wave length corresponding to a color temperature equal to 6500 degrees Kelvin measured with a thermos-colorimeter Gossen and shielded with translucent boards (Digital Photography Review http://www.dpreview.com/). 
A further problem of the low-cost cameras consists in the production of aliasing biases; they appear, sometimes, in the digital images when these include grids with very fine meshes. This problem is due to the presence of extra signals, in the sampled signal, with frequency values external to those belonging to the spectrum. Therefore, the resulting signal is compatible with several signals, each denominated alias of other one. The following Figure 6 shows how, sampling from two different signals, one obtains the same numerical values, for the points marked in yellow, of the sampling range.

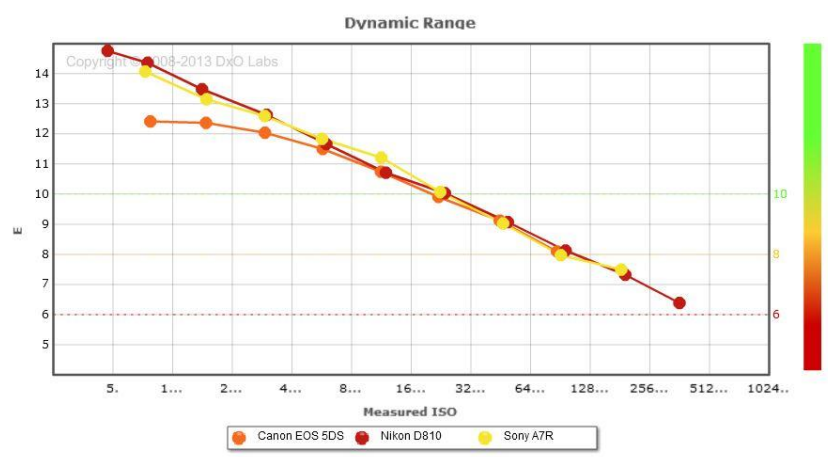

Figure 5. Dynamic range

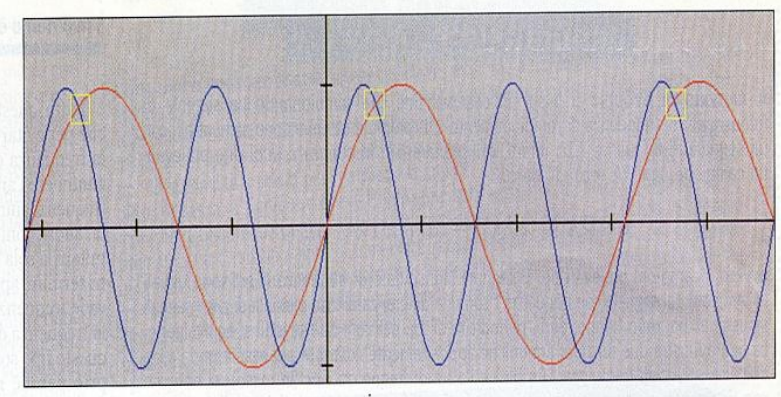

Figure 6. Image aliasing

As far as data elaboration is concerned, current softwares require ten of images, necessarily transformed from the almost-analogical raw format of the cameras sensors to the jpeg one. This operation involves a loss of information with respect to the tiff format of the images, whose storage requirements could result too high for the current informatics standards, producing several giga-byte files for the images. Hence, being mandatory to elaborate jpeg images, it is indispensable that the object is photographed as a whole, without excluding even the smallest area.

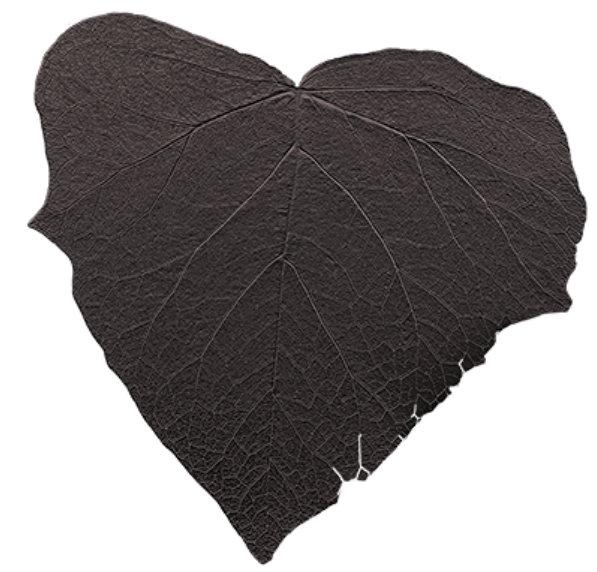

Figure 7. Vector mesh

The products of the elaboration are either the vector mesh represented in Figure 7, whose volumetric identification can be made with any CAD software, or the three-dimensional models shown in Figure 8 in scale 1:1. Superimposing two subsequent meshes allows one to establish the dimensions of the bunches and of the leaves of the grapevine.

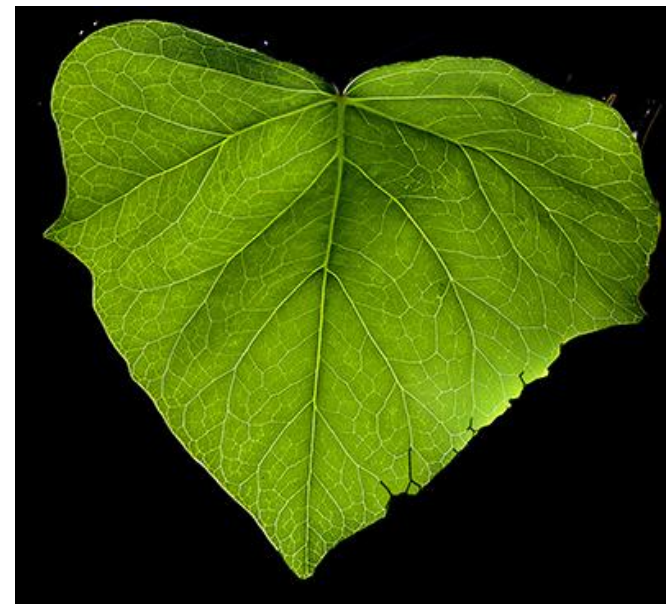

Figure $8.3 \mathrm{D}$ model in scale 1:1

In addition, the vector mesh of the vine leave as well as the $3 \mathrm{D}$ model allow one to analyze the shape of the leaves and to measure the principal and secondary ribbing, of the edges width, of the border and of the apex.

\section{GEOGRAPHICAL FRAME OF SITES AND CHARACTERISTICS OF TILLAGES}

The images have been taken in the archaeological area of Boscoreale, inside the old Roman domus of Oplontis, a domus of small dimensions (about 450 meters square); it was destined to wine production and had a wine-store containing 18 buried "dolia" and a "torcularium" with a vessel for wine pressing and a buried "dolium" for gathering the first must.

This famous sub-urban Roman domus, whose erection dates back to the end of the $1^{\text {st }}$ century a.D., was one of the greatest wine producers of the town already on the $2^{\text {nd }}$ century a.D. Actually, all the land surrounding the domus was a vineyard, as it has been proved by the excavations in the area; in particular, holes made from the grape roots and the stakes supporting grapevines have been discovered in the old 
countryside table. Fruit trees and a small orchard were found as well.

Planimetry of the domus exhibits an almost articulated shape determined from subsequent enlargements and refurbishments. Under the patronage of the Special Superintendence for the Archaeological Heritage of Napoli and Pompei, a vineyard has been planted in some of the areas of the domus by using exactly the same old technique of tillage used in the viticulture of two thousand years ago; it has reproduced on the basis of the castes of the vine roots.

\section{PHOTOGRAMMETRIC STEREOSCOPIC SHOOTING}

\subsection{Stereoscopic Acquisition}

The stereoscopic shooting has been necessary for a threedimensional vision, otherwise impossible with the same precision by using alternative approaches. Actually, in this way, one can obtain images that provide shape, volume, dimensions and the grapevine species by means of a threedimensional image.
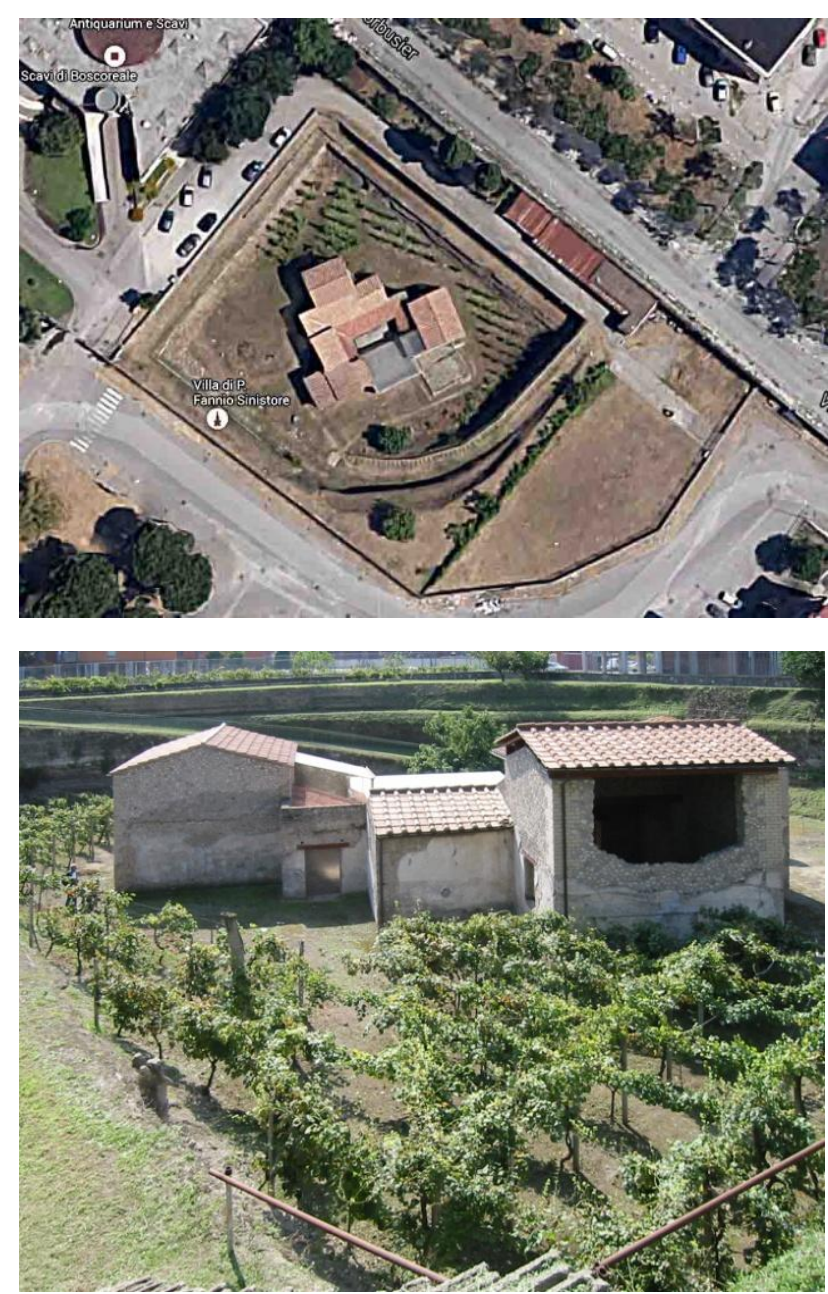

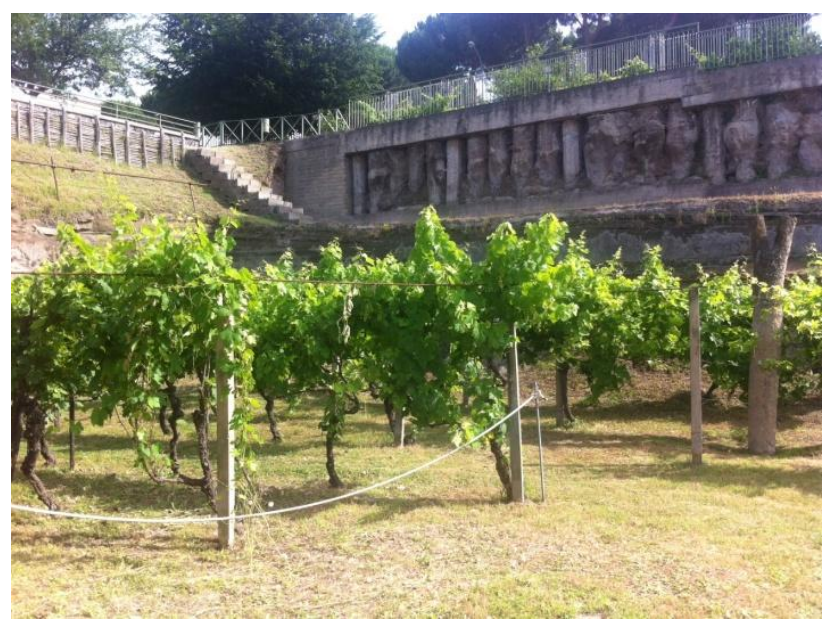

Figure 9a, 9b e 9c. Autochthonous Boscoreale's vine

The advantage for oenologists and experts of the field is to obtain information about the ripening of the grapes, about the eventual necessity of making loppings, strippings of leaves, the presence of illnesses and parasites.

The shooting of the Boscoreale's autochthonous vine has been made by a Nikon D810 metric camera, calibrated with a Zeiss Otus $50 \mathrm{~mm}$ optics, as shown in Figure 10. The calibration parameters of the camera are reported in Table 1 . Images are raw analogical files that must be converted to tiff images in "a digital dark camera" without lack of information.

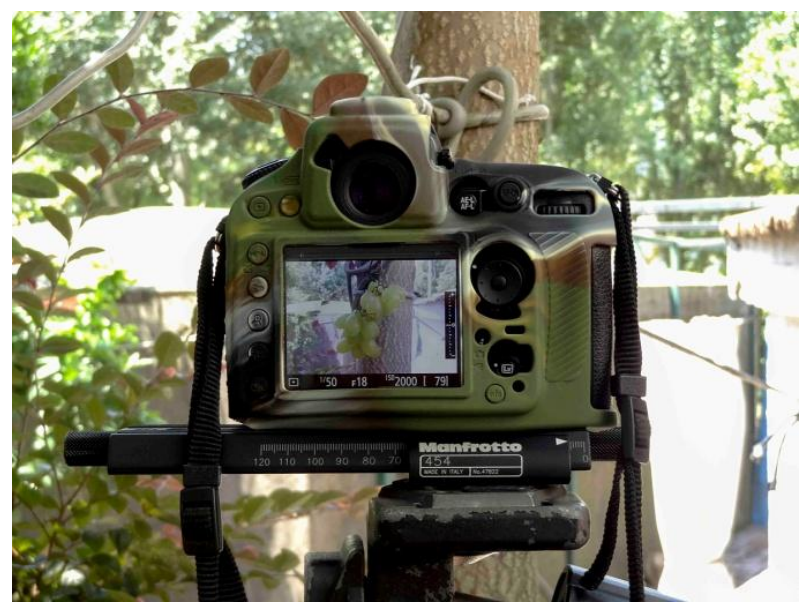

Figure 10. Metric camera and optics

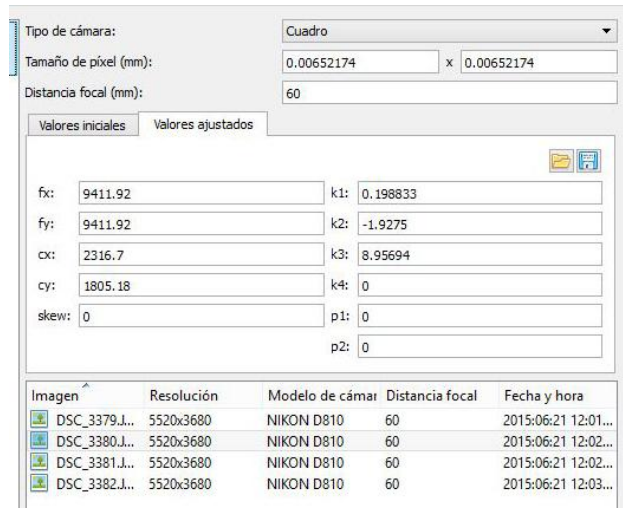

Table 1. Calibration parameters of the Nikon 810D camera 
After having fixed the camera to a micro-metric plate, firmly connected to a tripod, two stereoscopic shootings have been made at the regular distance of about 6.5 centimeters, for reproducing the binocular vision of the human eyes, denominated "stereopsi", i.e. the natural three-dimensional stereoscopic vision of the man (Fryer et al., 2007).

The two shootings produce an anaglyph, represented in Figure 11, that allows for a traditional stereoscopic vision, and an eventual MPO, Multi Picture Object, file as shown in Figure 12; this last one, on the contrary, allows for a stereoscopic digital vision which can be seen with active glasses on a monitor as in a videogame.

The image in Figure 12, relative to a MPO file, is obtained from two shootings, not yet merged in a unique threedimensional image by means of a dedicated software. In fact a MPO file is a raster file that can be generated from a very high number of shootings, successively converted in an anaglyph by using a specialized software for elaborating stereoscopic images.

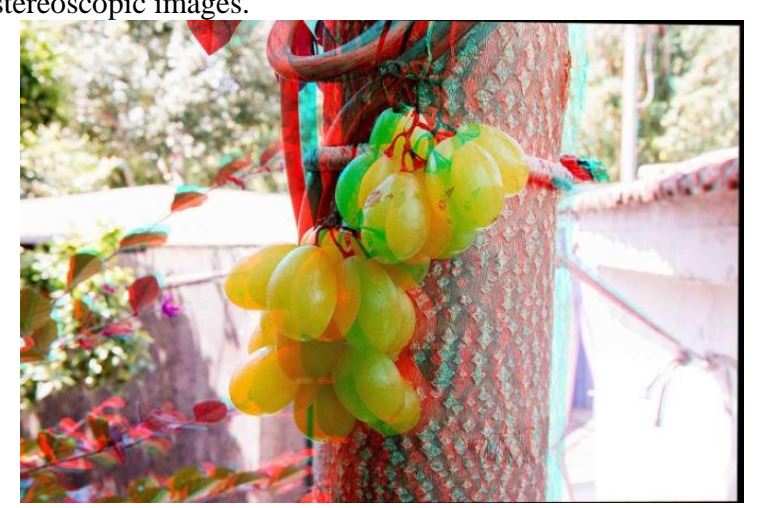

Figure 11. Traditional anaglyph

Hence, although both the traditional anaglyph and the threedimensional MPO image have been obtained from the same shots taken with the same camera and optics, the difference between the two images is represented only by the final vision that is more user-friendly with the MPO file. In fact the use of the red-light blue glasses, necessary for the vision of traditional anaglyph, has been eliminated in the MPO file (D'Urso et al., 2014).

In this respect we remind that filtering of the red-light blue glasses creates difficulties to the persons affected by visual problems. On the contrary the MPO file represents the new frontier of the three-dimensional stereoscopic vision, though having the operative limit of requiring computer screens with specified frequencies and active glasses.

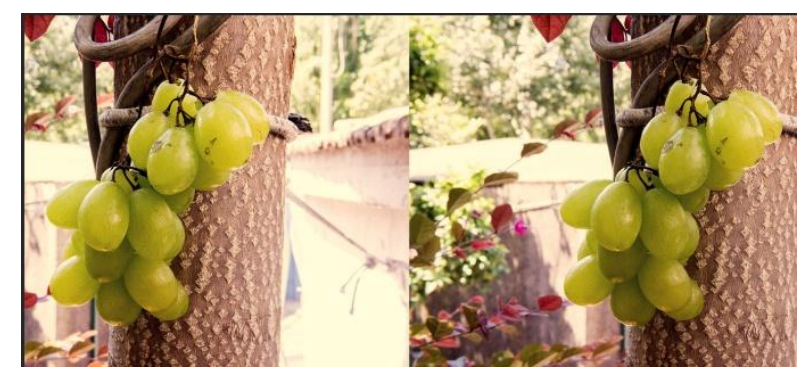

Figure 12. Stereoscopic images of a MPO file

Moreover, using the same shooting procedure described for the vine leaves, volume of the grapes and of the acini of the grapevine has been obtained as well. Actually, as for the leaves, stereo-couples of images have been produced for a single grape or acinus and a mesh has been first generated and subsequently elaborated in CAD. In this way it is possible to generate orthophotos and projections of any kind for the generic acinus, either from the top or from the bottom (Aguilar et al., 2010).

The three-dimensional vision of the grapes and of the single acinus allow for a total evaluation of the shapes, features, colors and, hence, of the repening degree of the acinus, thus allowing for a correct choice of the data of harvesting and wine-making. All these aspects are fundamental for the wine quality and the described approach of the illustrated technique is of easy access and widely usable for producers and oenologists.

\subsection{Photogrammetric elaboration}

The same shootings can be used for obtaining, through suitable software elaboration of the image data, threedimensional numerical models that permit the creation of real copies.

In particular, n.5 images have been acquired for a leaf and elaborated with Agisoft Photoscan. The photogrammetric shootings, made in laboratory, in a controlled environment with respect to all parameters required for a close-range shooting, have been acquired at the distance of 60 centimeters by a calibrated Nikon camera whose features are reported in the following table:

\begin{tabular}{|l|l|}
\hline \multicolumn{2}{|c|}{ Camera characteristics } \\
\hline Camera Model & NIKON D810 \\
\hline Resolution & $4912 \times 7360$ \\
\hline Focal lenght & $60 \mathrm{~mm}$ \\
\hline Pixel size & $4.92 \times 4.92 \mu \mathrm{m}$ \\
\hline
\end{tabular}

A stereoscopic visualization of the leaf , i.e. a 3D anaglyph that can be watched with the red-light blue glasses, is represented hereafter.

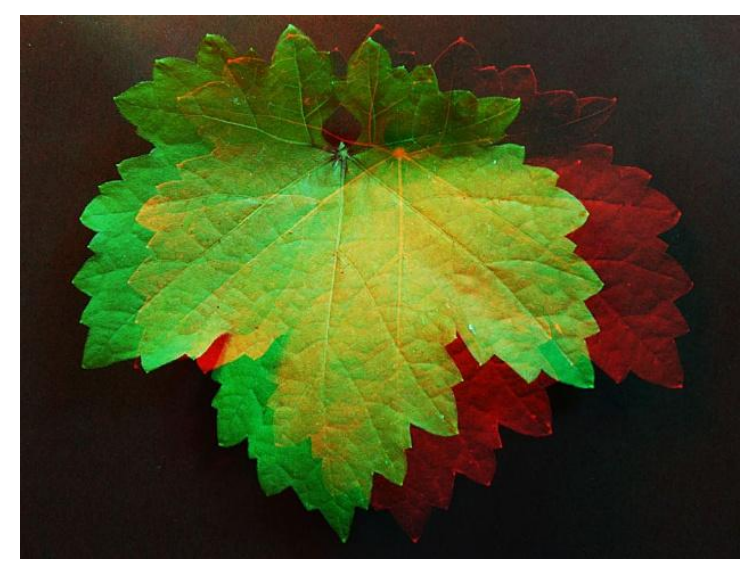

Figure 13. Anaglyph of the leaf of autochthonous vine

For what concerns elaboration with the Agisoft software, a spread cloud of 115756 points, once the outliers have been eliminated, has produced a dense cloud of 34853 points, 11507 of which have been tie points (Engels et al., 2006). The vector mesh, represented in Figure 14, has a planimetric precision of the order of thousandths of millimeter and inferior to the millimeter for the third dimension, $\mathrm{z}$. 
In fact, from a 60 centimeters distance of view and with a focal distance of 60 millimeters, one obtains a scale factor in the plane of image, equal to the value 10 .

$$
m_{b}=\frac{h}{c}=\frac{600}{60}=10
$$

The vector mesh of the vine leaf, elaborated with the Agisoft Photoscan software and represented in the Figure 14, has been exported in CAD and redrawn using a graphics table with an electron aerograph (Wacom Cintiq 27QHD). The mesh, projected on the $(\mathrm{x}, \mathrm{y})$ plane, provides the planimetric dimensions of the leaf, as here represented. Since the leaf width is equal to 9 centimeters and the number of images equal to 5, the basis of shooting has a value of 18 millimeters. Accordingly, known the precision in the image space, $\sigma^{2}$, equal to the projection error of 0.492 pixel $=0.492 \times$ $4.92=2.4206 \mu$ icron, the precisions of restitution in the $(\mathrm{x}, \mathrm{y})$ plane are exactly equal to the half of the pixel dimension. In fact they turn out to be:

$$
\sigma_{x}=\sigma_{y}=m_{b} \sigma^{2}=10 \times 2.4206=2.4206 \mu \text { icron }
$$
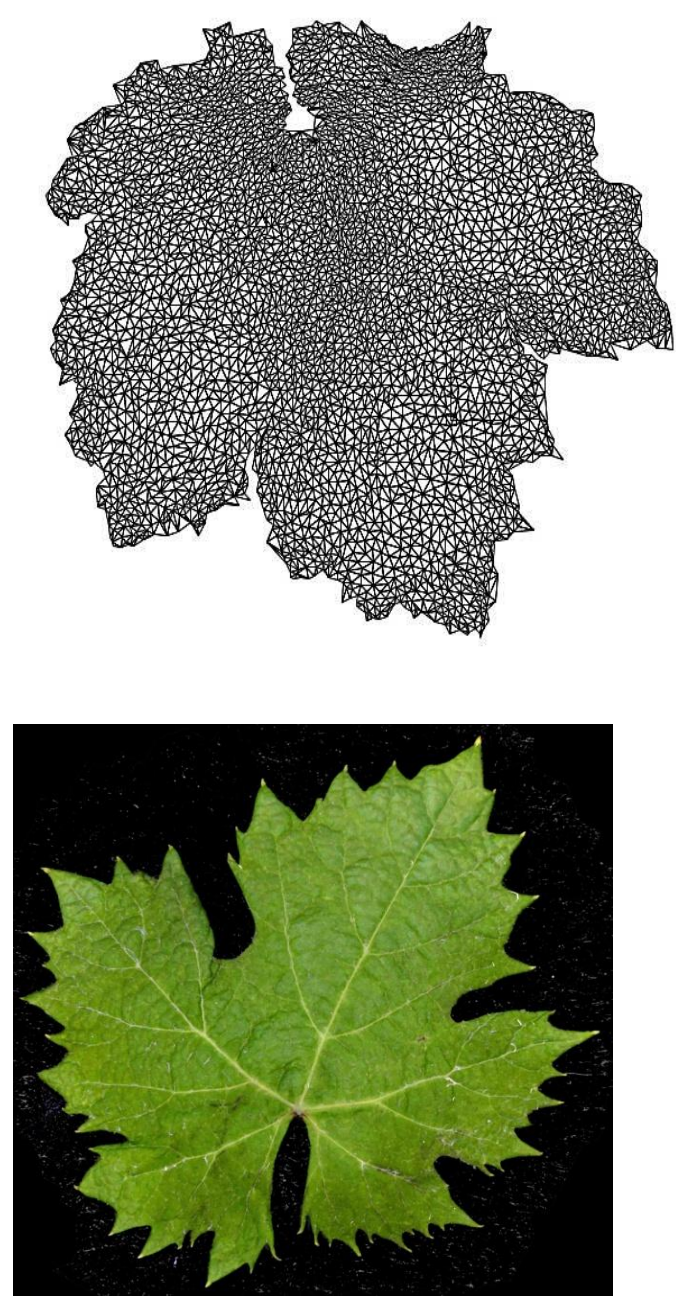

Figure 14. Vector mesh and orthophoto of the leaf of the Boscoreale vine

and the precision along the $\mathrm{z}$ axis is:

$\sigma_{z}=m_{b} \times \frac{h}{b} \times \sigma^{2}=10 \times \frac{600}{18} \frac{\times 10^{3}}{10^{3}} \times 2.420=0.807 \mu$ icron

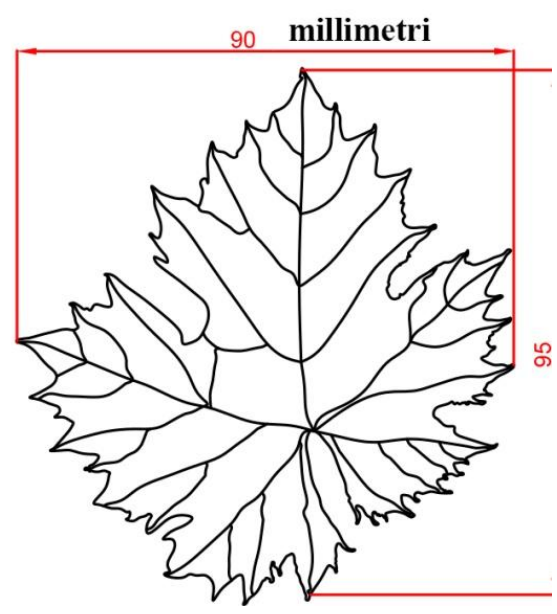

Figure 15. Projection on the plane (x,y)

The texture in the $(\mathrm{x}, \mathrm{y})$ plane of the mesh allow one to obtain the graphic of the digital botanic atlas reported in figure 16 , a); this can be compared with the drawing reproduced in the table of the traditional botanic atlas that is reproduced in Figure 16, b). In the first image the contours of the edge and of the structural nervations are notably more marked.

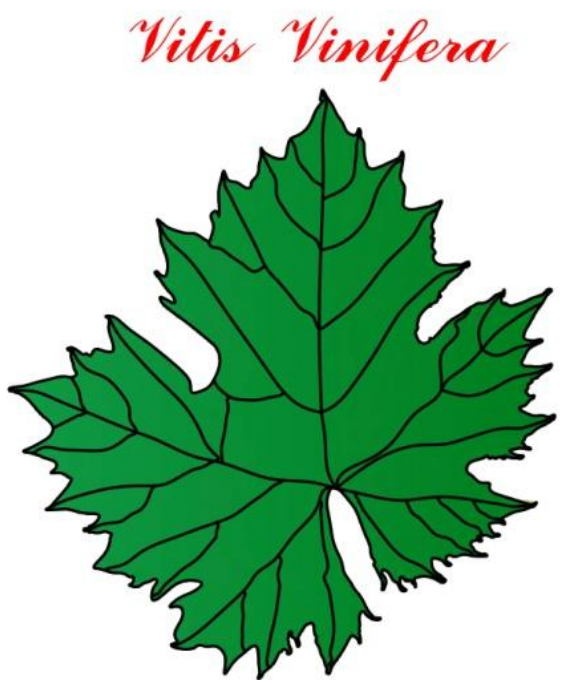

a)
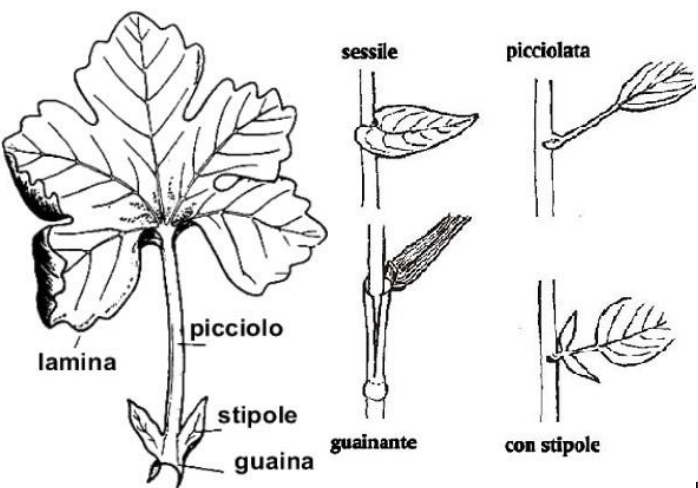

b)

Figure 16. a) Digital botanic atlas - b) Traditional botanic atlas 
Moreover, CAD graphics can be superimposed to the realized orthophotos in order to assess, quantitatively and qualitatively, the state of preservation of the vine by means of coloring variations visible either with the natural light or with particular ultra-violet or infra-red lights (Figure 17).

The $3 \mathrm{D}$ vector files that report for the grapes the dimensional values of the leaves and of the bunches accurately determine the growth degree of the tillage and allow one, as already shown, to project these dimensional values in several planes. Successively these projections can be transferred on acetate sheets and permit a rapid control of the growth through a simple superimposition of samples.

The creation of three-dimensional models by numeric control machines is another possibility to check the degree of growth. In this case an exact copy of the leaf and /or the bunch of the grape is realized in polystyrene, in MDF, Medium Density Fibre-board, or HDF, high density model.

The fruit of the vine is the grape that, from a botanic aspect, is an infructescence due to the transformation of the inflorescence of the cultivation. The grape of the Boscoreale's vine presents approximately an extended shape of about 1520 centimeters. The acini have a light green colour with an oval shape, a longitudinal average growth of 27.6 millimeters, diameter of 18.33 millimeters and an average weight of about 2.5 grams.

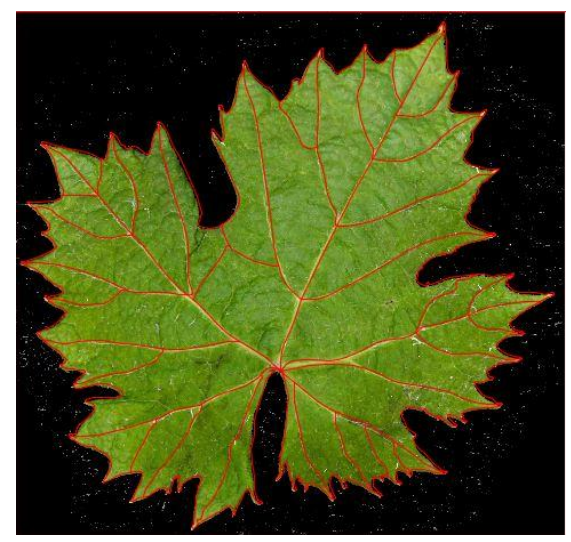

Figure 17. CAD image superimposed over an orthophoto

By using the same elaboration technique for the 3D model of the leaf, an ortophoto of a single acinus of the grape has been produced by elaborating 24 images using Agisoft Photoscan. Figure 18 shows, on the left, a longitudinal section of an acinus, obtained with a cut through an electronic lancet that has permitted the characterization of the seeds, and, on the right, a frontal measurement of the whole acinus of grape.
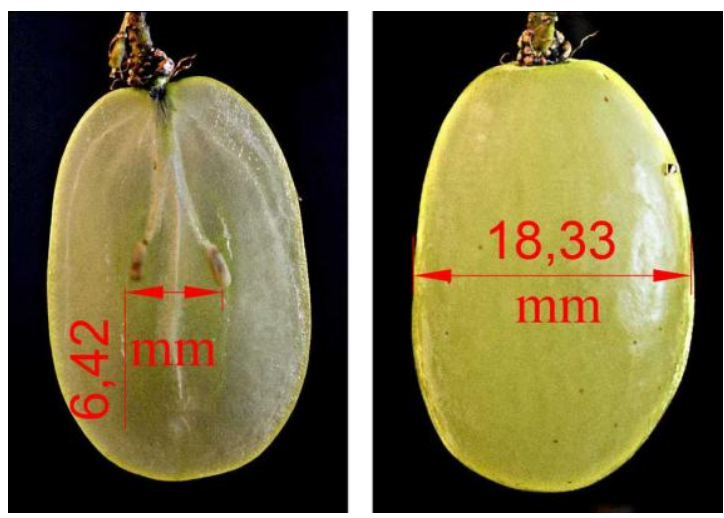

Figure 18. Section and frontal view of a acinus
Weight, shape and volume of the acini vary in accordance with the seasonal trend of the ripening level. The liquid part of the acinus, i.e. the must, is constituted by water $(68 \%$ $86 \%$ ) and the pulp; this is the most fundamental component either from the technological and quantitative since it contains the greatest part of substances in suspension or in solution of the water. When the grape is mellow the weight of the pulp and of the must are equivalent, the median part of the pulp, the most plentiful, is the richest one in the sugar content (more than 20\%) but the poorest one in the tannin content.

Following the acinus growth, three fundamental phases are illustrated in the figure 19:

herbaceous period: great quantities of malic acid and sugar are formed for the photosynthesis;

veraison period: acinus increase continues and the amass of sugar begins. The chlorophyll disappears and the color appears, initially as spread speckles and successively painting the whole acinus;

ripening period: a consistent amass of sugar is obtained, the acidity decreases due to oxidation of the acini and to neutralization by potassium and calcium.

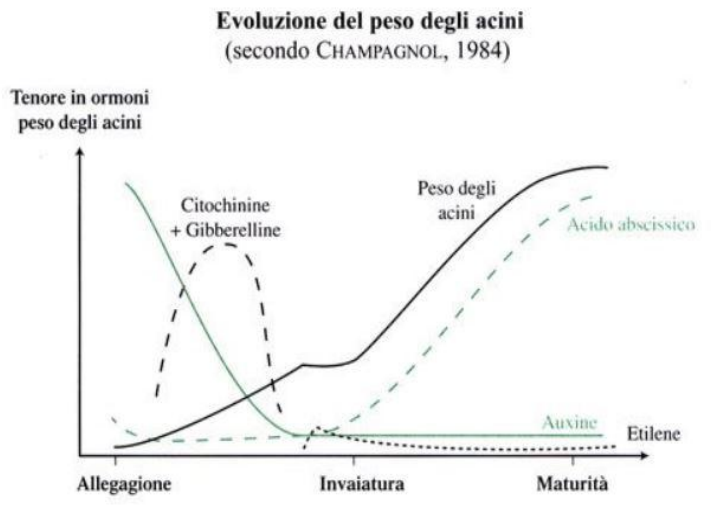

Figure 19. Growth of the grape

\section{CONCLUDING REMARKS}

An application of close-up photogrammetry has been detailed with the aim of supplying digital botanic atlases of vine-yards with the same figurative features as the traditional ones drawn by hand; such features are intended as cognitive entities reflecting the sensory properties of grapes in the human mind.

In this respect very high resolution cameras have been used in order to reproduce reality with the maximum likelihood. Moreover the optical-mechanical limits of the low-cost instrumentations have been pointed out, especially in terms of the reduced width of the dynamic range. This last property can be responsible of total lack of detail in areas characterized by high contrast lights and/or shadows. Digital measurements of grape leaves and acini allow to the botanists, oenologists and all operators of the viticulture sector to analytically determine variations of shapes and of volumes of the grape. These are due to several graftings made on grapes in order to make them more resistant to the illness, thus and improving quality and productivity. 
This last issue strongly depends on the market demands since absence of seeds is required for producing grapevine to be eaten; vice-versa an increase of alcoholic degree is required for the grapes used for wine-making. Hence a detailed knowledge of the tillage features is necessary in a market which is becoming more and more demanding and competitive. This is particularly true in regions where the high quality standards of wine production justify the adoption of site -specific management practices to simultaneously increase both quality and fruit yield.

The measurement technique exploited in the paper and the relevant results have to be intended as basic elements of a suitable protocol in viticulture amenable to future and forreaching objectives. In particular more extensive and demanding field sessions will be carried out to establish how many grape samples, measured by the proposed methodology, can become representative of the vine-yard health status and how they can be related to the ground conditions.

In this sense the approach presented in the paper can represent a further example of the precision viticulture that seeks to exploit the widest range of available observations, through unmanned aerial vehicles (UAVs), aircraft or satellites, (Kavvadias et al., 2015; Ishimwe et al., 2014) to describe the vineyards spatial variability with high resolution and provide recommendations to improve management efficiency in terms of quality, production and sustainability.

\section{REFERENCES}

Aguilar M.A., Pozo J.L., Aguilar F.J.,Garcia A.M., Fernàndez I., Negreiros J., Sanchez-Hermosilla J.

(2010)" Application of close-range photogrammetry and digital photography analysis for the estimation of leaf area index in a greenhouse tomato culture" International Archives of Photogrammetry, Remote Sensiong and Spatial Information Sciences, Vol.XXXVIII, Part 5, Commission V Symposium, Newcastle upon Tyne, UK, 5-10

Bouguet, JY. "Camera Calibration Toolbox for Matlab." Computational Vision at the California Institute of Technology.

http://www.vision.caltech.edu/bouguetj/calib doc/

Bradski G.,Kaehler A. Learning OpenCV : Computer Vision with the OpenCV Library O'Reilly, Sebastopol, CA, 2008

Chandler, J. H., Fryer, J. G. and Jack, A. (2005), "Metric capabilities of low-cost digital cameras for close range surface measurement" The Photogrammetric Record, 20: 1226; doi: 10.1111/j.1477-9730.2005.00302.x

Dey D., Mummert L., Sukthankar R. (2012) "Classification of Plant Structures from Uncalibrated Image Sequences" The Robotics Institute, Carnegie Mellon University

Digital Photography Reviewhttp://www.dpreview.com/

D'Urso M.G. , Marino C., Rotondi A.. (2014) "On 3D dimension: study cases for archaeological sites" The International Archives of the Photogrammetry, Remote Sensing and Spatial Information Sciences,Volume XL-6, 2014, ISPRS Technical Commission VI Symposium, 19 - 21 May 2014, Wuhan, China

\section{DxOMark http://www.dxomark.com/}

Engels C., Stewenius H., Nister David (2006) "Bundle Adjustment rules" The International Archives for Photogrammetry, Remote Sensing and Spatial Information
Sciences, Symposium ISPRS Commission 3, Vol.XXXVI, part 32006

European Parliament -Directorate General for International Policies Policy department Study "Precision Agriculture: An opportunity for EU farmers- Potential support with the Cap 2014-2020"

Fryer, J.G., Mitchell, H.L. and Chandler, J.H. (eds.), 2007. Applications of 3D Measurement from images" Whittles Publishing, ISBN 978-1870325-69-1

Ishimwe R., Abutaleb K., Ahmed F. (2014) " Applications of Thermal imaging in agriculture- A review " Advanced in Remote Sensing 3, 128-140; http://dx.doi.org./10.4236/ars.2014.33011

Kavvadias A., Psomiadis E., Chanioti M., Gla E., Michas S. (2015) " Precision Agriculture-Comparison and Evaluation of innovative Very High Resolution (UAV) and Landsat Data" Proceedings of the 7th International Conference on Information and Communication Technologies in Agriculture, Food and environment (HAICTA 2105), Kavala, Greece, 17-20 september 2105, 376-386

Zeiss Carl AG Camera Lenses 73446 Oberkochen, Germany, www.zeiss.com/photo 